\title{
L'HOMME L'Homme
}

Revue française d'anthropologie

157 | janvier-mars 2001

Représentations et temporalités

\section{Fenella Cannell, Power and Intimacy in the Christian Philippines}

Cambridge, Cambridge University Press, 1999, XXVI + 312 p., gloss., append., bibl., index, fig., cartes, ph. (« Cambridge Studies in Social and Cultural Anthropology » 109)

\section{Charles Macdonald}

\section{(2) OpenEdition}

\section{Journals}

Édition électronique

URL : http://journals.openedition.org/lhomme/5882

DOI : 10.4000//homme.5882

ISSN : 1953-8103

Éditeur

Éditions de l'EHESS

\section{Édition imprimée}

Date de publication : 1 janvier 2001

Pagination : 317-319

ISBN : 2-7132-1357-6

ISSN : 0439-4216

Référence électronique

Charles Macdonald, "Fenella Cannell, Power and Intimacy in the Christian Philippines », L'Homme [En ligne], 157 | janvier-mars 2001, mis en ligne le 23 mai 2007, consulté le 21 septembre 2020. URL : http://journals.openedition.org/lhomme/5882 ; DOI : https://doi.org/10.4000//homme.5882

Ce document a été généré automatiquement le 21 septembre 2020

(C) École des hautes études en sciences sociales 


\section{Fenella Cannell, Power and Intimacy in the Christian Philippines}

Cambridge, Cambridge University Press, 1999, XXVI + 312 p., gloss., append., bibl., index, fig., cartes, ph. (« Cambridge Studies in Social and Cultural Anthropology » 109)

\section{Charles Macdonald}

1 CE LIVRE de Fenella Cannell, qui enseigne à la London School of Economics, est le résultat d'une étude ethnographique de la région de Bicol, aux Philippines. Bien que rattachée par la géographie physique à Luçon, Bicol appartient par la géographie humaine à ce « mezzogiorno » des Philippines que sont les îles visayannes.

2 L'ouvrage se compose de trois parties principales qui, dans l'ancienne ethnographie, auraient pu s'intituler « Parenté », " Magie » et « Religion ». Une quatrième partie, plus brève, consiste en une discussion sur les « concours de beauté ». On a donc affaire en quelque sorte à une suite d'essais reliés les uns aux autres par une discussion théorique qui les situe dans un contexte local - philippin - et régional - Sud-Est asiatique. L'auteur a tendance à présenter ces quatre aspects de la vie locale, à savoir le mariage, les pratiques des guérisseurs, les représentations centrées sur la mort, enfin les concours de beauté de travestis, comme des paradigmes de la vie culturelle de cette région et, plus largement peut-être, de celle des basses terres chrétiennes de l'archipel.

Fenella Cannell a enquêté en 1988-1989 dans une municipalité située non loin de Naga City, la capitale de la Province. La paysannerie de cette région rurale pauvre dépend pour sa subsistance de l'agriculture et de la pêche. L'agriculture repose sur une petite propriété foncière et sur le métayage/fermage, voire sur le travail saisonnier. Ces activités ne fournissent guère de quoi hisser la majorité de cette population au-dessus du seuil de pauvreté en dépit des revenus occasionnels du petit commerce de détail et de ceux, plus importants, des travailleurs migrants. C'est donc avec raison que l'auteur considère les thèmes du dénuement, de la misère, de la marginalisation et de l'aliénation comme centraux dans la culture rurale de cette région. Elle trouve d'ailleurs à ce sujet des mots qui émeuvent. On ne peut parler de la culture de ces paysans sans rappeler qu'il s'agit de gens « qui n'ont rien » et qui fantasment à perte de 
vue sur l'opulence d'une civilisation tentatrice et inaccessible qui les entoure et les obsède, dont ils accrochent les emblèmes (photos de télévisions, de frigidaires, de voitures de luxe) à leurs murs, images du jardin édénique dont ils sont à jamais exclus et auxquelles ils rendent un culte naïf et émouvant. C'est d'ailleurs un thème repris dans le dernier chapitre consacré aux concours de beauté. Fenella Cannell interprète ceux-ci comme l'appropriation symbolique des insignes de la modernité et de la richesse, "l'Amérique du cœur", comme l'écrivait un romancier philippin, avec cependant l'idée qu'il s'agit aussi d'une sorte de «négociation politique ». Avant de considérer ces interprétation théoriques plus générales, voyons quelle matière ethnographique nous offre ce livre.

4 Comme on l'a dit, la première partie concerne le mariage et la parenté. À travers des exemples bien choisis, l'auteur privilégie le motif de la négociation des attitudes et des statuts d'autorité entre fille et parents, mari et femme. En tant que contrat entre groupes, le mariage tend aussi à nier l'asymétrie de l'alliance, à transformer les alliés en consanguins et à parler des époux en termes de germanité, comme c'est le cas dans bien d'autres sociétés des basses terres de la région. Sont ainsi décrits les préliminaires, la négociation sur la prestation et les rites accompagnant le mariage.

5 La deuxième partie traite des pratiques thérapeutiques dans le cadre des cultes aux esprits. Les médiums sont possédés par un ou plusieurs esprits familiers, et la relation ambivalente qui s'établit ainsi est l'objet d'une analyse subtile. L'auteur débrouille les aspects divers de ce complexe de croyances et de pratiques portant sur différentes sortes d'esprits et d'êtres surnaturels, sur le sens du sacrifice, sur le prix (en fait sa gratuité de principe) de la prestation thérapeutique, sur les types de possession (multiples, à connotation chamanique ou non), sur les éléments syncrétiques en rapport avec le culte catholique, sur les amulettes, enfin sur l'institution curieuse des « anniversaires » d'esprits familiers.

6 La troisième partie est de loin la plus solide et la plus intéressante. Ce qui n'est pas pour surprendre puisqu'elle s'attache à ce qui, dans ce contexte, est le mieux structuré et le plus fondamental: les éléments de la culture chrétienne. En réunissant autour du thème de la mort les différentes institutions que sont le traitement des morts ordinaires, la dévotion pour la figure du Christ gisant et le culte des saints, l'auteur fait preuve d'un rare discernement. Car c'est bien autour du passage de la vie à la mort que se nouent les représentations qui structurent la vision de l'homme dans ce monde. L'accent n'est pas mis sur l'eschatologie, mais sur les relations entre le monde des esprits des défunts et celui des vivants. Moins que le destin des morts, c'est le destin des vivants par rapport aux morts qui importe. Ce qui explique le soin apporté à l'embaumement, l'insistance sur la notion de dette dans les lamentations funéraires et l'importance des rites de la Toussaint.

7 Le Christ gisant, descendu de la croix mais non encore enterré, est un objet majeur de vénération. Tout se passe comme si ce moment du cycle de la Passion était détaché des autres et donnait naissance à une figure divine à laquelle était rendu un culte distinct, à l'instar d'un saint à part entière. En outre, cette figure a bien une vie propre en tant qu'idole, au point que les fidèles attribuent une réalité quasi biologique à son image en bois. Mais surtout, elle fournit le modèle même du traitement du mort ordinaire. Chaque défunt est une sorte de Christ mort et chaque cérémonie funèbre un moment de la Passion. Ce Christ est celui pour lequel on ressent de la "pitié » (herak), tout comme pour le disparu des veillées funéraires familiales. 
8 L'assimilation du Christ gisant au mort ordinaire va plus loin. Elle se lit dans le parallélisme entre enterrement et procession du Vendredi saint, lamentations et lecture du texte de la Passion (Pasión). On sait, depuis les travaux de l'historien Reynaldo Ileto, que ce texte qui décrit la vie du Christ est le fondement des représentations populaires et la source où sont venus puiser pratiquement tous les mouvements insurrectionnels, en tout cas chez les Tagals. Sa lecture ritualisée, dont Fenella Cannell fait un rapport circonstancié, reste donc bien le cœur vivant de cette culture chrétienne populaire qui caractérise la société rurale des basses terres. Le pagtapat, joute verbale qui se greffe sur cette lecture, est la preuve supplémentaire qu'une réelle culture populaire a assimilé le christianisme en le retravaillant de l'intérieur et lui a prêté des formes inspirées par un art de la parole plus ancien et plus indigène.

9 Si la figure du Christ est incorporée à la communauté, celles des saints l'est aussi de différentes façons. D'abord leurs statues sont la propriété de familles particulières. Ils possèdent des terres et ont des revenus. Ils sont membres d'un groupe de parenté. En ce sens, le Christ est un saint comme un autre, mais dont la famille s'étend à l'ensemble de la communauté. Ensuite, on leur fait des "promesses ", et singulièrement celle de consacrer des enfants à la performance de rôles dans le mystère de la Passion. Il est dommage qu'à ce sujet l'auteur n'ait pas fait le rapprochement, pourtant frappant, avec les rites de sinsin que j'ai décrits à Palawan.

10 Le dernier chapitre porte à la fois sur les concours de beauté et sur les homosexuels ou travestis qui jouent dans ceux-ci un rôle prépondérant. J’ai déjà mentionné la valeur de « médiation » que Fenella Cannell leur reconnaît, dans un sens profane bien entendu. Je remarquerai simplement que sa discussion aurait mérité une allusion aux prêtre bissu des Bugis, petite lacune dans la culture pourtant très étendue de l'auteur.

11 Voilà pour l'ethnographie. Mais celle-ci, telle l'embryon, baigne dans un milieu ambiant nourricier : le liquide amniotique de la théorie. Il faut donc en parler, et, par là même, de l'économie générale de l'ouvrage. Connaissant l'auteur pour un esprit brillant et cultivé, et par ailleurs observatrice attentive et scrupuleuse, il me peine de dire le fond de ma pensée. Car je trouve cet ouvrage mal agencé et certaines de ses démarches de pensée me dérangent.

12 Premièrement, il m'apparaît plus comme un recueil d'articles que comme un propos unifié, ce qu'il prétend être. Les différents essais qui le composent sont très artificiellement soudés les uns aux autres. Il me semble aussi que les considérations théoriques prennent trop de place par rapport à l'étude des faits. Chaque bribe d'information donne lieu à une dissertation dont le but est d'authentifier ladite information par un calibrage avec les modèles en cours dans les études sur le Sud-Est asiatique (notion de "pouvoir » selon Benedict Anderson, « État-théâtre » à la Clifford Geertz, «économie morale » du paysan de James Scott, «maisons» au sens de LéviStrauss, modèle centro-périphérique de Shelly Errington et consort, etc.). Plutôt que d'éclairer la réalité par la théorie, l'auteur semble passer son temps à assouvir l'appétit insatiable de monstres paradigmophages en leur donnant en pâture des études de cas et des extraits d'interviews.

13 Cela m'amène à soulever deux points qui ont peut-être plus d'importance sur le cours des recherches actuelles en anthropologie de l'Asie du Sud-Est. Le premier est lié à la perspective historicisante de ces études. Excellente dans son principe lorsqu'elle s'appuie sur des reconstructions partielles et hypothétiques et qu'elle réfère à un état 
très lointain et partant extrêmement schématique de la société, elle prête le flanc à la vieille critique fonctionnaliste qui dénonçait les spéculations historiques sans fondement. L'auteur n'est d'ailleurs pas aveugle à ce fait. Elle se rend compte que les sociétés tribales, aussi hiérarchisées qu'elles aient été au moment du contact avec les Espagnols, n'étaient pas des paysanneries. Les comparaisons avec les travaux de Janet Carsten $^{1}$ sont utiles et fécondes, mais signalent aussi un contraste profond entre la situation malaise et celle qu'on trouve à Bicol.

Le second point concerne la pente normative que prennent certains de ces textes. Fenella Cannell ne fait pas mystère de son souci de redorer le blason des cultures des basses terres de l'archipel, injustement accusées, d'après elle, d'être dépourvues de «culture » (intéressante ambiguïté sur ce terme). Elle s'emploie donc à monter une entreprise de réhabilitation allant dans le sens de la critique postmoderne (dénonciation de l'orientalisme et d'une vision « coloniale ", rétablissement de la vérité qui veut que toute communauté soit « imaginée » et toute tradition "inventée ») afin de récupérer l'ethos non contaminé du paysan philippin. Elle se trouve bien dans une réinterprétation de ce qui est le fond de la culture des Philippines, à savoir le christianisme. Cela, l'auteur l'a fort bien vu et il faut lui rendre cette justice.

Toutefois, certaines des remarques faites précédemment n'enlèvent rien à la valeur de l'ouvrage qui contient de merveilleuses observations et des analyses pénétrantes et justes. Il mérite qu'on le lise. Et puis, même si elles assaisonnent trop généreusement le plat ethnographique, toutes les idées si généreusement dispensées au fil des pages donnent de l'appétit pour mieux comprendre ce type de culture sans « culture ».

\section{NOTES}

1. Cf. Janet Carsten, The Heat of the Hearth. The Process of Kinship in a Malay Fishing Community, Oxford, Clarendon Press, 1997 (« Oxford Studies in Social and Cultural Anthropology »). [Voir le compte rendu de cet ouvrage dans L'Homme, 2000, 154-155 : 761-763. Ndlr.]

\section{AUTEUR}

\section{CHARLES MACDONALD}

CNRS, Institut de recherche sur le Sud-Est asiatique (IRSEA), Université de Provence, Marseille. 